\title{
Extracting River Features from Remotely Sensed Data: An Evaluation of Thematic Correctness
}

\author{
Josef HECHER $^{1}$, Anthony FILIPPI ${ }^{2}$, Inci GUNERALP ${ }^{2}$ and Gernot PAULUS ${ }^{1}$ \\ ${ }^{1}$ Carinthia University of Applied Sciences, Villach/Austria·Josef.Hecher@edu.fh-kaernten.ac.at \\ ${ }^{2}$ Texas A\&M University, College Station/USA
}

This contribution was double-blind reviewed as full paper.

\begin{abstract}
Automatic feature extraction from satellite imagery is cost effective and fast. An essential issue in this context is the degree of accuracy for thematic correctness obtainable through common pixel-based and object-oriented classification algorithms. By applying two classification algorithms to Landsat $5 \mathrm{TM}$ imagery for the extraction of different morphological river features the thematic correctness of the resulting raster images and the separability of the river features is evaluated.

River features of meandering rivers evolve through dynamic avulsion, erosion and deposition processes. Although many studies focus on the analysis of these river environments, diverse methods of GIS and remote sensing based river feature classification methods have not been evaluated and assessed yet. In the literature several techniques to monitor spatio-temporal changes such as lateral river channel migration are already mentioned but the tendency there is to identify the changes by examining time spans rather than a point in time. Besides that the semiautomatic river feature methods described in related studies mainly focus on the identification of a river channel itself and do not consider additional features such as oxbows, scars, relic channels, etc. that in fact are significant characters in riverine environments. Therefore, this paper evaluates the application of a supervised classification using ENVI's Support Vector Machine and an object based classification using the ArcGIS extension Feature Analyst to extract river features from Landsat 5 TM images including ancillary data files. Furthermore, the results of the classification methods are evaluated with regard to thematic correctness and separability of the various classified river features using accuracy assessment as presented in the specialist literature. Finally the long-time changes in the riverine environments are traced by interpreting the distribution of the classified river features. Accordingly, the approach of this work contributes to on-going research concerning semiautomatic or automatic river feature extraction.
\end{abstract}

\section{Introduction}

Rivers and streams are among the most powerful, important and remarkable forces on earth that form its appearance causing erosion and sediment deposition. For example the Mississippi River carries almost a billion tons of soil and rock per year to the Gulf of Mexico (LUTGENS \& TARBUCK 1995), enlarging Louisiana's area by about $35 \%$ within the 
last 6000 years due to sediment deposition. The avulsion processes associated with these forces play a crucial role in the occurring spatio-temporal river dynamics. Although avulsion processes in meandering rivers are nothing new and had always occurred, we are still not able to predict precisely the conditions leading to the avulsion of a meandering river (SLINGERLAND \& SMITH 1998). In fact, understanding the ways in which river channels have migrated through time is critical to tackling many geomorphologic and river management problems (YANG et al. 2002).Sooner or later avulsion processes are causing channel migrations changing the course and the appearance of a river. In historically terms rivers in the southeast of Texas have been strongly influenced by avulsions (BLUM \& ASLAN 2006). An example that depicts the power of rivers is the flood of the Yellow River in China in 1931. Almost four million people were killed. A flood in 1993 on the Mississippi River caused $\$ 15$ billion in property damages (LUTGENS \& TARBUCK 1995). However, these are only a few examples of how avulsion processes affect the shape of a landscape and manmade structures. Therefore in numerous study projects methods had been developed to extract river features and provide the attained data for on-going analysis of riverine environments. Manual digitization and classification using aerial photographs or satellite images are common ways to extract river features (PASSALACQUA et al. 2012). More recent approaches focus on the (semi) automatic extraction of objects in remotely sensed data (e.g., GRAZZINI et al. 2010; SUN et al. 2012). In order to find out how effective automatic extraction processes actually are, in this study two feature extraction methods will be applied and evaluated.

The main purpose of the study is to test different classification methods to map meander river features in the lower Brazos River (Texas) and evaluating their separability. Therefore, first it is necessary to understand the avulsion processes taking place in the project area and determine locations affected by avulsion processes along the river. Subsequently, representative places of avulsion have to be digitized and assigned to the respecttive river feature class according to the specialist literature. Furthermore, the river features in the study area have to be digitized manually. The main objectives are to perform automatic feature extraction methods using the Support Vector Machine (SVM) and Feature Analyst (FA) as well as to evaluate the results with regard to the thematic correctness.

\section{Study Area and Input Data}

The study area in this work is the lower Brazos River in Texas, USA. The section of the lower Brazos River begins nearby the Bryan-College Station metropolitan area and ends at its river delta in Freeport, Texas. Parts of the study area overlay the Houston-Sugar LandBaytown metropolitan area, which is the fifth largest in the United States (UNITED STATES Census Bureau 2011). The counties encompassed by the study area are: Brazoria, Fort Bend, Austin, Waller, Washington, Burleson and Brazos. The climate in the study area is subtropical with hot summers and mild winters.

The Brazos River is the largest river in Texas, encompassing a drainage area about $118.000 \mathrm{~km}^{2}$. Starting from his headwaters in New Mexico, the river flows into the Gulf of Mexico after more than $1.900 \mathrm{~km}$ (PHILLIPS 2006).

Three different datasets form the basis for the analysis of the target area and the subsequent accuracy assessment. Two Landsat 5 TM scenes covering the target area divide the study 
area in an inland and a coastal region. The Landsat images, created in 2010, are provided by the US Geological Survey (USGS) in GeoTIFF format with a spatial resolution of $30 \times 30 \mathrm{~m}$ (Band 1-5 \& 7). The second dataset consists of a DEM from 2009 with the same spatial resolution and format representing the spatial character of the project area. The final dataset is a composition of seven $1 \times 1 \mathrm{~m}$ Color Infrared (CIR) DOQQs, provided by the National Agriculture Imagery Program (NAIP) from 2010 that serves as ground reference data. The format used is Multi-resolution Seamless Image Database (MrSID).

\section{Conceptual Model and Data (Pre-) Processing}

The entire workflow of the project is separated into four phases and is presented in figure 1 . The two classification methods are applied in phase three followed by the Accuracy Assessment. At the beginning of the project the Landsat 5 scenes had to be pre-processed in order to minimize process time and enhance the information content of the satellite images. By applying filter and transformation methods to the adapted Landsat 5 scene, new information was derived from the respective image. The image filter operators Sobel, Roberts and Gaussian High Pass are performing edge detection methods to enhance and sharpen the river features' edges (JENSEN 2004). Additional layers are generated by utilizing data transformations, such as Tasseled Cap (KAUTH \& THOMAS 1976) and Normalized Difference Vegetation Index (NDVI) (RouSE et al. 1974), for vegetation mapping as well as for vegetation index calculation.

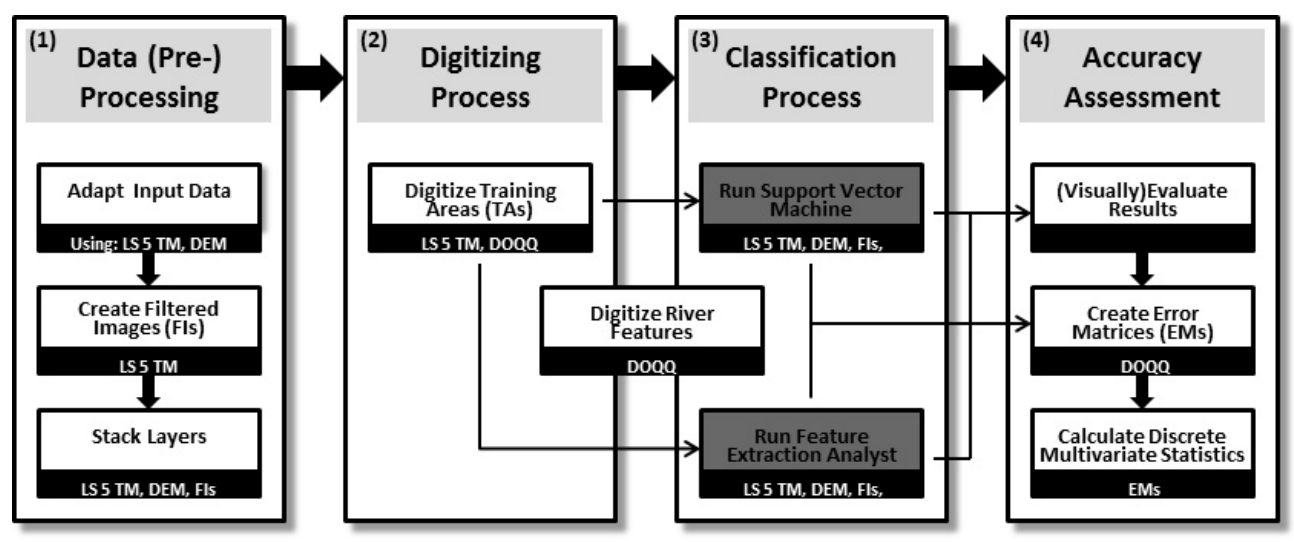

Fig. 1: Conceptual project workflow model

The newly derived data layers are stacked with the Landsat image as ancillary data files deploying diverging layer combinations. The purpose here is to test the effect of varying stacking combinations on the classification results. A fundamental principle thereby is the identical alignment of the grid cells of all stacked data layers including the DEM. The detailed approach of the first project phase is sketched in figure 2. 


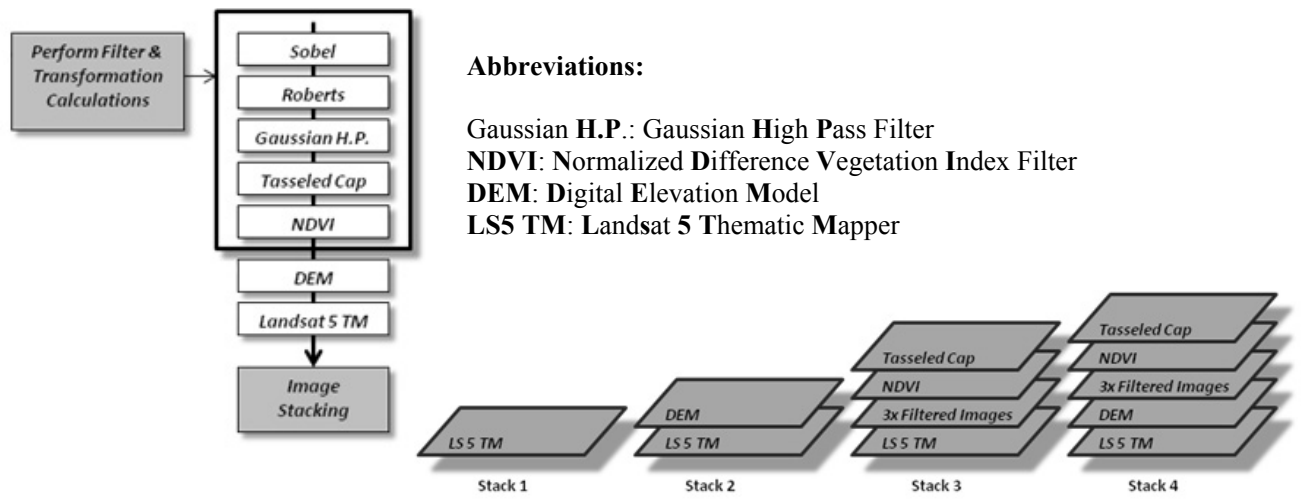

Fig. 2: Image enhancement methods and resulting stacking combinations

\section{$4 \quad$ Extracting River Features}

\subsection{Digitizing Process}

According to the literature the features are divided into five separate classes: River Channel, Oxbow, Scar, Relic Channel and Sandbar. Due to the fact that relic river channels are defined as features that can be both dry as well as watery and moistly, this feature is separated into two subclasses. After the definition of the feature classes training areas of each class are sampled in the form of polygons that follow the shape of the respective feature (figure 3). The resulting polygon shapefiles are the essential input data for the subsequently performed automatic classification processes. Concerning the training areas, only river features that belong to the Brazos River or have certainly been formed by the Brazos River are digitized. Consequently, spectral variability within feature classes can be minimized and posterior performed Accuracy Assessment will also only focus on Brazos River features. However, the newly derived training areas represent each of the predefined river feature classes. The adequate training areas are identified with the aid of DOQQs as well as Google Earth images.

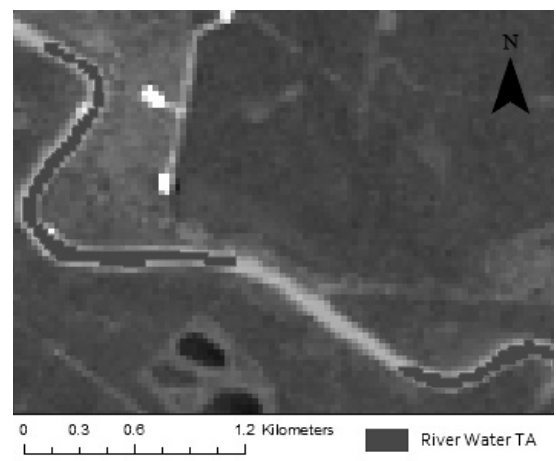

Fig. 3:

Digitized training areas (TA) following the shape of a river water feature

In addition to the digitization of the training areas a second digitization process comprises the manual digitization of all river features in the entire study area using the DOQQs. Even 
though this process is time intensive, the manually digitized polygons are necessary for subsequent analysis and the accuracy assessment. In this case manual digitization is supposed to deliver relatively accurate results in vector format without applying any intermediate steps. The higher accuracy is primarily attained because of the higher spatial resolution of the DOQQs $(1 \times 1 \mathrm{~m})$ compared to the Landsat scene $(30 \times 30 \mathrm{~m})$. Consequently even very narrow morphological elements could have been digitized. Taking into account the difference in resolution between LS 5 and the DOQQ this would have led to an unfair comparison of the classification results. As the primary focus lies on the thematic correctness and not on completeness of the classification output, only those features have been digitized that were "big" enough for a subsequent identification of SVM or FA. In other words, despite the higher resolution of the DOQQs, there was no essential change in the digitizing process concerning the minimum mapping unit. A big advantage of the manual vectorization is the ability to directly ignore non relevant objects due to the competences of human comprehension. However, it has to be considered that manual digitization procedures are not barred from (human) error.

\subsection{Classification Process}

Two supervised classification algorithms are executed that automatically assign the river features to their river feature classes. The first applied classification method is run with ENVI's Support Vector Machine (SVM) and Feature Analyst using ESRI's ArcMap10 as platform. Both classification processes perform their analysis on the same input data files: the four stacked raster files and the manually digitized Training areas pertaining to the Landsat 5 image. SVM follows a pixel based classification approach that focuses on the spectral signatures of pixels. The inputs of a support vector machine are called feature vectors that represent the training objects. By using a kernel functions SVM maps the objects into a high- or infinite dimensional feature space. Then the main task of SVM is to calculate hyperplanes in the space that separate the training objects into classes. The data objects that are closest to the hyperplane form the critical basis of a training set (figure 4). In ENVI's SVM an optional probability threshold parameter enables to mark pixels with probability values outside of the limits as unclassified (PAKHALE \& GUPTA 2010).

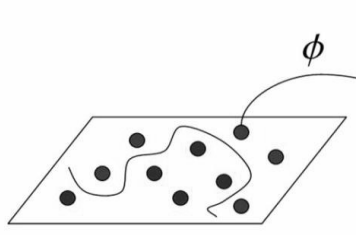

Input Space

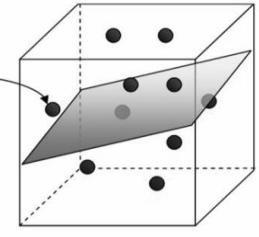

Feature Space
Fig. 4:

Principle of Support Vector Machines (IMTECH 2006)

In the SVM first the training areas shapefiles are exported as ENVI Vector Files (.evf) and defined as a Region of Interest for one of the selected stacked input files. The Radial Basis Function is chosen as kernel type and the Classification Probability Threshold is set to a value between $90 \%$ and $98 \%$.

In contrast to SVM, Feature Analyst (FA) as an object-oriented classification method does not only focus on the pixels' spectral signature, but also on the spatial information such as 
texture or form. In other words FA considers both spectral and spatial context when performing a classification. Object-oriented classification programs identify image objects that are characterized by spatial and spectral homogeneity (BENZ 2001). Apart from that no special image segmentation operations have been performed. The objects, or image segments, are then classified by conventional methods such as nearest neighbor, minimum distance, maximum likelihood, etc. Hence, FA benefits from the digitization of training areas that follow the shape of the river features. The settings used for the FA classification have been selected automatically by FA's artificial intelligence algorithm. As Input Representation the Bull's Eye 2 pattern at a width of 17 pixels has been chosen. In the FA classification workflow hierarchical learning has not been performed because it can be regarded as a post classification process that would derogate a fair comparison between SVM and FA results (BLASCHKE et al. 2008).

When the classification processes are completed, the output files are evaluated visually. Depending on the sampled training areas, selected options, such as probability threshold, or the input files themselves, the generated images are varying significantly. Hence several output files are created and evaluated before the best are exported as GeoTiff files. In the next step the two relic channel subclasses are merged since they have only been separated prior to the classification process due to their spectral heterogeneity. Since the main aim is to compare the direct output of the classification processes to evaluate the separability of the river feature classes, the "raw" classified raster images will form the basis for the Accuracy Assessment in the final phase of the study. However, to perform a visual comparison between the manually digitized and the semi-automatic classified images, the appearance of classified river features has to be enhanced. Therefore, the river features of the GeoTiff file are edited utilizing post processing tools such as sieving and clumping to delete isolated and aggregate clustered pixels. Finally, the edited features are converted into simplified polygons to resemble the actual shapes of the real river features.

\subsection{Accuracy Assessment}

The final study phase involves the evaluation and interpretation of the different classification output files to identify the best result and to analyze the separability of the river features involved. All automatically classified images are evaluated visually to identify the best results in terms of completeness, logical consistency and appearance in general as part of pre-selection. The selected raster images form the basis of further accuracy assessment methods to evaluate their thematic accuracy and the separability of the five river feature classes. Thematic correctness of the classified raster files is evaluated by sampling more than 50 single pixel points per feature class using a stratified random sampling scheme (CONGALTON \& GREEN 1999). The sampling unit for the Accuracy Assessment is single pixel as the preexisting pixel size is $30 \times 30$ meters, which is relatively coarse. Due to the fact that the training area sampling was only focused on Brazos River features, also the Accuracy Assessment is applied to the regions close to the Brazos River. Consequently, classified pixel areas that are not within the zone of influence of the Brazos River can be ignored and are disregarded. This is realized by clipping the classified pixels to the extent of the manually digitized river features.

By comparing the pixel values of the classified raster files to the DOQQs Error matrices are generated for the respective classified image. For further evaluation of the error matrices 
the User's Accuracy (CONGALTON 1986) (Equation 1), as well as the Kappa Coefficient (Coefficient of Agreement) (COHEN 1960) (Equation 2) are calculated. The Kappa Coefficient is a discrete multivariate statistical measure that describes the qualitative (thematic) agreement of the classified elements in the generated raster images. The User's Accuracy estimates the probability of correctly classified pixels, or in other words: classified pixels in the image represent the actual class or category on the ground (STORY \& CONGALTON 1986).

$$
\begin{aligned}
& \text { User's Accuracy } i=\frac{n_{i i}}{n_{i+}} \\
& \hat{K}=\frac{n \sum_{i=1}^{k} n_{i i}-\sum_{i=1}^{k} n_{i+} n_{+i}}{n^{2}-\sum_{i=1}^{k} n_{i+} n_{+i}}
\end{aligned}
$$

\section{Equation 1:}

User's Accuracy; correctly classified pixels per class $\left(n_{i i}\right)$; sum of classified pixels per class $\left(n_{i+}\right)$

Equation 2: Kappa coefficient ( $\hat{K}$ ); number of classes $(k)$; correctly classified pixels per class $\left(n_{i i}\right)$; sum of classified pixels per class $\left(n_{i^{+}}\right)$; sum of reference pixels per class $\left(n_{+i}\right)$; sum of pixels in entire matrix (n)

\section{$5 \quad$ Results and Discussion}

The results of the study show that river features have been extracted successfully using automatic GIS based classification methods. The thematic accuracy of the generated output images varies based on the applied classification algorithm and the stacking of the input files. In general, Feature Analyst delivers more accurate results than the Support Vector Machine. Table 1 is a comparison of three assessed images. The three input files for the classification were two six bands Landsat images (SVM I and FA) and a stacked image including a DEM, Sobel filter, NDVI and Tasseled Cap bands (SVM II). The User's Accuracy values are varying between the feature classes and images. SVM is able to separate the first three feature classes with accuracy values higher than $80 \%$. Using the stacked image as input file SVM was not able to classify any scar cells. It is noteworthy that the relic channel class has been classified more accurate in the FA trial. The classification methods reached a coefficient of agreement value of $64.19 \%$ (SVM I), $59,93 \%$ (SVM II) and 67,56 \% (FA). FA can be considered as one of the best results of all classifications while SVM II is one of the worst results. Surprisingly, SVM classification inputs including the DEM led to lower accuracy values in the resulting images while the appending of NDVI and Tasseled Cap bands enhanced the accuracy.

Table 1: Comparison of Accuracy values

\begin{tabular}{|l|l|l|l|l|}
\hline \multicolumn{2}{|c|}{} & SVM I & SVM II & FA \\
\hline \multirow{4}{*}{ User's Accuracy } & river water & $96,67 \%$ & $93,33 \%$ & $96,67 \%$ \\
\cline { 2 - 5 } & sandbar & $86,67 \%$ & $82,00 \%$ & $68,00 \%$ \\
\cline { 2 - 5 } & oxbow & $80,00 \%$ & $81,82 \%$ & $78,33 \%$ \\
\cline { 2 - 5 } & scar & $56,41 \%$ & NA & $43,33 \%$ \\
\cline { 2 - 5 } & relic channel & $26,00 \%$ & $18,18 \%$ & $83,33 \%$ \\
\hline \multicolumn{2}{|l|}{ coefficient of agreement } & $64,19 \%$ & $58,93 \%$ & $67,56 \%$ \\
\hline
\end{tabular}


Figure 5 is a classification output image using Feature Analyst. The classified features were clipped to the digitized features to execute the evaluation of the thematic correctness. The green u-shaped features are oxbow lakes filled with water or moisture. scars are dry oxbows filled with sediment. The relic channel features indicate a former course of the river that has changed through constant lateral migration caused by erosion and sedimentation processes. In this area, mainly the class relic channel is confused with other classes, such as river water and oxbow.

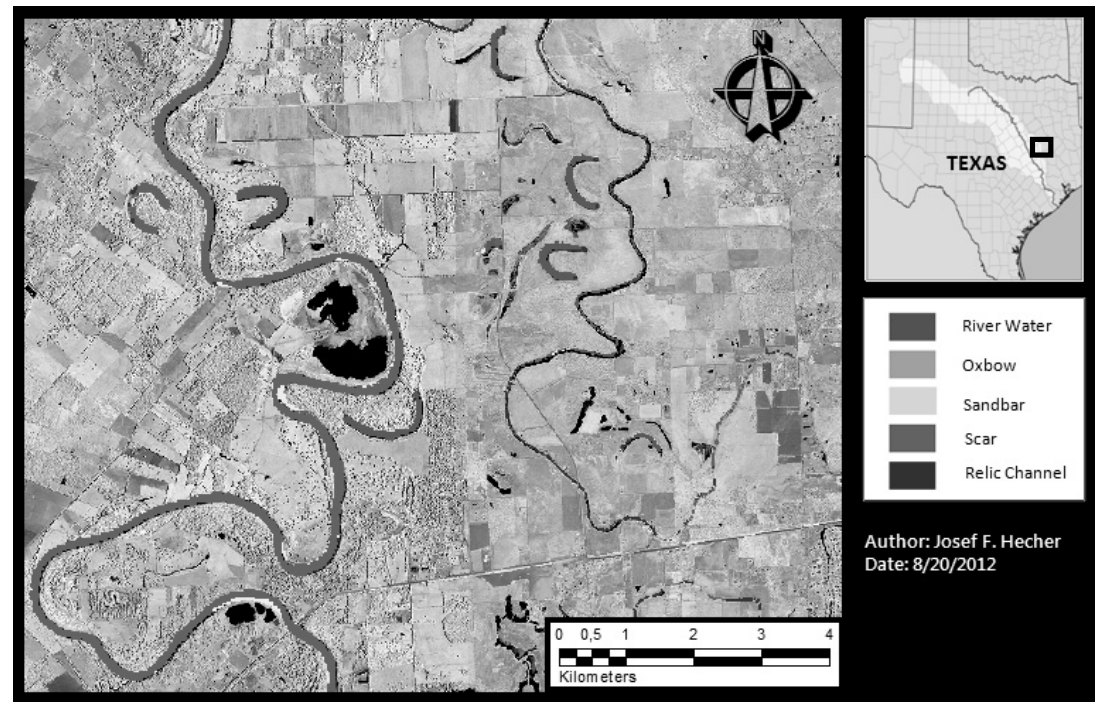

Fig. 5: Classified river features using FA; Brazos River, Tx.

\section{Conclusion and Outlook}

The purpose of this research was to test the separability of several river features by using automatic classification methods. For the performance of the advanced pixel based method ENVI's SVM was used. The object based classification was run with the Feature Analyst. Both methods require the digitization of representative training areas of the respective river features. The training areas have been digitized on two Landsat 5 scenes that covered the study area, the lower Brazos River basin, TX. Simultaneously, high resolution DOQQs served as verification images. To the Landsat scenes several image enhancement operations were applied for the subsequent raster file generation yielding additional information content. The enhanced as well as the original Landsat scenes were then combined with a DEM and served in different combinations as input files for the classification methods. Thereafter, the classified output images have been evaluated and compared visually. The best output files formed the basis for subsequent Accuracy Assessment methods to determine their thematic correctness and the separability of the examined river features.

The results show that SVM and FA have quite similar User's Accuracy values. Especially Relic Channel features are confused with other classes such as Oxbow or River Water. 
Possible reasons therefore are similarities in the spectral signature of the classes as well as the coarse spatial resolution of the input images. However, SVM successfully distinguished between river water, sandbar and oxbow features. In comparison, Feature Analyst only had problems with the classification of the Scar features. The result of the FA classification showed a slightly better Kappa accuracy than the SVM classification. For more accurate results in both classification methods high resolution data as well as the performance of additional post-processing methods would be necessary.

Future research in this field should be based on high resolution data and Feature Analyst Software. Consequently the spectral characteristics of narrow features such as small Relic Channels that have wooded banks can be captured much easier and enhance the thematic correctness of the classified image. In addition, algorithms based on logical connectives should be implemented that help to classify features which certainly belong to a river. Sandbars for example only occur in river bends and are very close to water level, so therefore a rule has to be implemented. With the usage of a shape based object recognition algorithm the confusion between usual lakes and u-shaped oxbow lakes formed by river erosion could be minimized (ISAKA \& SAKURAI-AMANO 1995). With these algorithms it would be possible to ignore or delete features that have been misclassified and preserve those that in fact are actual river features.

\section{References}

BENZ, U. (2001), Definiens Imaging GmBH - Object-Oriented Classification and Feature Detection. IEEE Geoscience and Remote Sensing Society Newsletter, 16-20.

BlaschKe, T., LANG, S. \& G. HAY (2008), Object Based Image Analysis: Spatial Concepts for Knowledge-Driven Remote Sensing Applications. Berlin, Springer, $162 \mathrm{pp}$.

BluM, M. D. \& ASlAN, A. (2006), Signatures of climate vs. sea-level change within incised valley-fill successions: Quaternary examples from the Texas Coastal Plain. Sedimentary Geology, 190, 177-211.

CoHen, J. (1960), A coefficient of agreement for nominal scales. Educ. Psychol. Measurement, 20 (1), 37-46.

CONGALTON, R. G. (1986), Using spatial autocorrelation analysis to explore errors in maps generated from remotely sensed data. Photogramm., 54 (5), 587-592.

Congalton, R. G. \& Green, K. (1999), Assessing the Accuracy of Remotely Sensed Data: Principles and Practices. Boca Raton, FL:Lewis Publishers.

Grazzini, J., Dillard, S. \& SoIlle, P. (2010), A new generic method for the semi automatic extraction of river and road networks in low and mid-resolution satellite images.

IMTECH (2006), Principle of Support Vector Machines (SVM). Retrieved August 242012 from http://www.imtech.res.in/raghava/rbpred/svm.jpg.

IsAKa, J. \& SAKURAI-Amano, T. (1995), Geoscience and Remote Sensing Symposium, 1995. Quantitative Remote Sensing for Science and Applications.

Jensen, J. R. (2004), Introductory Digital Image Processing: A Remote Sensing Perspective.

Kauth, R. J. \& Thomas, G. S. (1976), The Tasseled Cap-A Graphic Description of the Spectral Temporal Development of Agricultural Crops as Seen by Landsat. Proceedings, Symposium on Machine Processing of Remotely Sensed Data, West Lafayette. LARS, 41-51. 
Lutgens, F. K. \& TARbuck, E. J. (1995), Essentials of Geology. Englewood Cliffs, Prentice Hall.

Pakhale, G. K. \& Gupta, P. (2010), Comparison of Advanced Pixel Based (ANN and SVM) and Object-Oriented Classification Approaches Using Landsat-7 Etm + Data. International Journal of Engineering and Technology, 2 (4), 245-251.

Passalacqua, P., Belmont, P. \& Foufoula-Georgiou, E. (2012), Automatic geomorphic feature extraction from lidar in flat and engineered landscapes. American Geophysical Union, $2 \mathrm{pp}$.

PhILliPS, J. (2006), Field Data Collection in Support of Geomorphic Classification of the lower Brazos and Navasota Rivers.

Rouse, J. W., HAAs, R. H., Schell, J. A. \& DeERING, D. W. (1973), Monitoring the vernal advancement and retrogradation (green wave effect) of natural vegetation. Prog. Rep. RSC 1978-1, Remote Sensing Center, Texas A\&M University, College Station, p. 93.

Slingerland, R. \& SMITH, N. (1998), Necessary conditions for a meandering-river avulsion. Geology, Boulder, 26 (5), 435-438.

StORY, M. \& CONGAlton, R. (1986), Accuracy assessment: a user's perspective, Photogramm. Eng. Remote Sens., 52 (3), 397-399.

Sun, Y. J, CHEN, D. Z. \& QIŪ, Y. F. (2012), A Study of Lake Wetland Information Automatic Extraction Based on the Interpolation and Threshold Method. In: Advanced Materials Research.

THE Brazos River Authority (2010), Brazos River Basin. Retrieved July 72012 from http://www.brazos.org/generalPdf/Brazos_basin_watershed.pdf.

United States Census Bureau (2011), 2011 Population Estimates. Retrieved July 72012 from http://www.census.gov/popest/data/metro/totals/2011/tables/CBSA-EST201101.csv.

YANG, X., DAMEN, M. D. J. \& VAN ZUIDAM, R.A. (1999), Satellite remote sensing and GIS for the analysis of channel migration changes in the active Yellow River Delta, China. International Journal of Applied Earth Observation and Geoinformation, 1. 